\title{
Transgenerational seasonal timer for suppression of sexual morph production in the pea aphid, Acyrthosiphon pisum
}

\section{AUTHOR(S):}

Matsuda, Naoki; Kanbe, Takashi; Akimoto, Shinichi; Numata, Hideharu

\section{CITATION:}

Matsuda, Naoki ...[et al]. Transgenerational seasonal timer for suppression of sexual morph production in the pea aphid, Acyrthosiphon pisum. Journal of Insect Physiology 2017, 101: 1-6

\section{ISSUE DATE:}

2017-08

URL:

http://hdl.handle.net/2433/230141

\section{RIGHT:}

(c) 2017. This manuscript version is made available under the CC-BY-NC-ND 4.0 license

http://creativecommons.org/licenses/by-nc-nd/4.0/; The full-text file will be made open to the public on 01 August 2018 in accordance with publisher's 'Terms and Conditions for Self-Archiving'; この論文は出版社版でありません。引用の際 には出版社版をご確認ご利用ください。; This is not the published version. Please cite only the published version. 
Transgenerational seasonal timer for suppression of sexual morph production in the pea aphid, Acyrthosiphon pisum

Naoki Matsuda ${ }^{\mathrm{a}}$, Takashi Kanbe ${ }^{\mathrm{b}}$, Shin-ichi Akimoto ${ }^{\mathrm{b}}$, Hideharu Numata ${ }^{\mathrm{a}, *}$

${ }^{a}$ Graduate School of Science, Kyoto University, Sakyo, Kyoto 606-8502, Japan

${ }^{\mathrm{b}}$ Graduate School of Agriculture, Hokkaido University, Sapporo, Hokkaido 060-8589, Japan

* Corresponding author at Graduate School of Science, Kyoto University, Sakyo, Kyoto 606-8502, Japan. Tel.: +81 75753 4073; fax: +81 757534113

E-mail addresses: numata@ethol.zool.kyoto-u.ac.jp (H. Numata) 


\section{ABSTRACT}

Many aphid species switch reproductive modes seasonally, with the sexual generations appearing in autumn. Sexual generations are induced by short days. It has been reported that the appearance of sexual morphs is suppressed by a transgenerational factor (a seasonal timer) over several generations after hatching from overwintered eggs. The present study examined whether the seasonal timer measures the number of days from hatching or the number of generations from hatching using the pea aphid, Acyrthosiphon pisum Harris (Homoptera: Aphididae). Effects of temperature and photoperiod on the seasonal timer were also examined by successive rearing. The ability to produce sexual morphs was strongly suppressed in stem mothers (the foundress generation), and gradually recovered over successive generations produced during a few months. The duration for which the seasonal timer could function depended on the number of days from hatching and temperature, but not on photoperiod or the number of generations from hatching. We thus showed in a single study that the seasonal timer of the pea aphid has all the physiological characteristics shown in separate studies in different aphid species.

Keywords: Acyrthosiphon pisum, photoperiodism, seasonal timer, sexual polyphenism, temperature

Abbreviations: LD, long-day conditions; SD, short-day conditions; GLMM, generalized linear mixed model 


\section{Introduction}

Insects adapt to inappropriate seasons for growth and reproduction through phenotypic plasticity, including diapause and seasonal morphs (Koštál, 2011). At higher latitude, photoperiod and temperature are major environmental signals that determine whether insects undergo direct development or diapause, and other seasonal traits (Nijhout, 2003; Nylin and Gotthard, 1998; Saunders, 2014). However, developmental events in the previous generation also have effects on these seasonal responses of the offspring (Denlinger, 2002; Mousseau and Dingle, 1991).

In many aphid species (Homoptera: Aphididae), seasonal morphs are regulated by photoperiod (Tagu et al., 2005): Viviparous parthenogenetic females are produced under long days, whereas oviparous sexual females and males are produced under short days. The effect of photoperiod on the reproductive modes was discovered in the strawberry root aphid, Aphis forbesi, as the first reported photoperiodism in animals (Marcovitch, 1923). Many aphid species successively reproduce more than ten generations by viviparous parthenogenesis during spring and summer. Sexual females and males appear in autumn and lay cold-hardy diapause eggs. In the next spring, after overwintering, only females (stem mothers) hatch from eggs and start to reproduce parthenogenetically (Moran, 1992).

Although photoperiods in spring when stem mothers become active are usually longer than those in autumn when sexual morphs appear, it is possible that aphids are subjected to photoperiods that induce sexual morphs in early spring. However, sexual morphs do not appear in spring in the temperate zone. Although the sensitivity to photoperiod is suppressed after termination of adult diapause and recovered after a 
certain delay in some insects (e.g., Hodek and Hodková, 1992; Shintani and Numata, 2010), it is peculiar to aphids that the suppression persists through several generations. In A. forbesi, sexual morphs do not appear over several generations from stem mothers even under short days (Marcovitch, 1924). In the vetch aphid, Megoura viciae, this phenomenon is thought to be controlled by a transgenerational factor referred to as an 'interval timer', which measures the number of days from hatching, but not the number of generations (Lees, 1960). In the present paper, we call this mechanism a 'seasonal timer' because the term 'interval timer' is also used for a mechanism that measures various durations of time in other contexts (Meyer et al., 2006; Nagao and Shimozawa, 1987; Saunders and Bertossa, 2011). Similar phenomena have been reported in other aphid species. In many previous studies, however, it was unclear whether the number of days or the number of generations from hatching is important (Campbell and Tregidga, 2006; Dixon, 1972, 1971; Dixon and Glen, 1971; Lushai et al., 1996; Margaritopoulos et al., 2002; Wilson, 1938). Temperature affects the duration for which the seasonal timer can function in $M$. viciae, whereas photoperiod has no effect on the duration in Aphis rubicola (Brodel \& Schaefers 1979; Lees 1960). Although the physiological and molecular mechanisms suppressing sexual morph production remain unknown (Tagu et al., 2005), determining the physiological characteristics of the seasonal timer might provide insights into these mechanisms.

The pea aphid, Acyrthosiphon pisum (Harris), is a suitable species for identifying the physiological and molecular mechanisms of the seasonal timer, because environmental conditions inducing sexual morphs have been extensively studied in this species (Kenten, 1955; Lamb and Pointing, 1972; MacKay, 1987), and its stem mothers can be obtained easily from sexual morphs produced in short-day conditions in the 
laboratory (Shingleton et al., 2003; Via, 1992). Moreover, the recent development of genome resources for this species has enabled transcriptomic approaches to identify the physiological and molecular mechanisms of the photoperiodism (IAGC, 2010; Ishikawa et al., 2012; Le Trionnaire et al., 2013). Bonnemaison (1972) showed that A. pisum has a seasonal timer: Sexual morphs did not appear in early generations derived from stem mothers. In the study by Bonnemaison (1972); however, it was not determined whether the duration of the seasonal timer depends on the number of days or the number of successive generations from hatching, or whether the temperature or photoperiod under which aphids were reared has effects on the duration of the seasonal timer.

The present study aimed to examine the physiological characteristics of the seasonal timer. First, we reared lineages of $A$. pisum that consisted of progenies born at different dates under a constant temperature and photoperiod to distinguish whether the seasonal timer measures the number of days or the number of generations. Then we reared aphids under different temperatures and photoperiods to examine the effects of the environmental factors on the seasonal timer.

\section{Materials and methods}

\subsection{Insects}

The ApL clone of A. pisum (referred to as Sap05Ms2 in Kanbe and Akimoto, 2009; named in Ishikawa et al., 2012) was used for experiments. This clone was collected in 2005 from Medicago sativa in Sapporo, Japan and has been maintained in 
the laboratory. Parthenogenetic females of this clone reared under short days and their progenies produce a small proportion and a large proportion of sexual morphs, respectively (Ishikawa et al., 2012). Parthenogenetic aphid cultures were maintained in plastic tubes ( $25 \mathrm{~mm}$ diameter, $100 \mathrm{~mm}$ depth) in which a seedling of the broad bean, Vicia faba, was maintained by wrapping a bean in wet paper under $16 \mathrm{~h}$ light and $8 \mathrm{~h}$ darkness (long-day conditions, LD) at $20.0 \pm 1.0^{\circ} \mathrm{C}$. The light intensity in the photophase produced by a daylight fluorescent lamp was $0.3-2.8 \mathrm{~W} / \mathrm{m}^{2}$.

To obtain stem mothers, oviparous females and males were produced under short days. One male and five oviparous females were placed together in a plastic case $(40.0 \times 40.0 \times 10.0 \mathrm{~mm})$ containing a leaf of broad bean under $10 \mathrm{~h}$ light and $14 \mathrm{~h}$ darkness (short-day conditions, SD) at $15.0 \pm 1.0^{\circ} \mathrm{C}$. These females laid eggs on the leaf or on the ceiling of the case after approximately 10 days. These eggs were used for experiments, except for those that did not darken within a few days and were judged as unfertilized (Miura et al., 2003). Fertilized eggs were kept under SD at $15.0 \pm 1.0^{\circ} \mathrm{C}$ for seven days, and then placed under constant darkness at $4.0 \pm 1.0^{\circ} \mathrm{C}$ for approximately three months to ensure embryogenesis (Shingleton et al., 2003; Via, 1992). These eggs were transferred to $\mathrm{SD}$ at $15^{\circ} \mathrm{C}$ and hatched within 10 days.

\subsection{Experimental design}

Stem mothers were divided into three groups on the day of hatching and reared under $\mathrm{SD}$ at $15^{\circ} \mathrm{C}, \mathrm{SD}$ at $20^{\circ} \mathrm{C}$, or $\mathrm{LD}$ at $20^{\circ} \mathrm{C}$. A maximum of 15 nymphs were reared on a single bean seedling. Each stem mother was transferred to a new seedling on the 
day of adult emergence, and started to reproduce in a few days.

To determine whether the seasonal timer measures the number of days or the number of generations from the hatching, the ability to produce sexual morphs was tested using aphids of two lineages reared in different ways. Progenies of the stem mothers reared under $\mathrm{SD}$ at $15^{\circ} \mathrm{C}$ were kept under the same conditions. After adult emergence, the number of asexual or sexual morphs was counted. A few nymphs that were born within three days of the larviposition onset (older-sisters) were transferred to new seedlings and used to start the 'older-sister SD lineage', whereas a few nymphs that were born approximately ten days after the larviposition onset (younger-sisters) were also transferred to new seedlings and used to start the 'younger-sister SD lineage' (Fig. 1A). Older- and younger-sisters of each generation were used to produce the subsequent generation in the older- and younger-sister SD lineages, respectively. In this way, aphids of the older- and younger-sister SD lineages were reared over a maximum of ten successive generations.

To examine the effect of temperature on the duration of the seasonal timer, the ability to produce sexual morphs was tested using aphids of lineages reared at different temperatures. Descendants of the stem mothers reared under SD at $20^{\circ} \mathrm{C}$ were kept under the same conditions, and the older- and younger-sister SD lineages were reared in the same way as those at $15^{\circ} \mathrm{C}$ (Fig. 1A). In addition to clones derived from overwintered eggs, the parental lineage (ApL) that had been maintained parthenogenetically since 2005 was used as a control for testing the ability to produce sexual morphs. Nymphs of the parental clone were transferred from LD to SD on the day of their birth and reared in the same way as the older-sister SD lineage at $15^{\circ} \mathrm{C}$ and $20^{\circ} \mathrm{C}$. 
To examine the effect of photoperiod on the duration of the seasonal timer, the ability to produce sexual morphs was tested using aphids reared under different photoperiods. The stem mothers reared under $\mathrm{LD}$ at $20^{\circ} \mathrm{C}$ were used to start 'the older-sister LD lineage' in the same way as that under SD (Fig. 1B). Progenies of these stem mothers were divided into two groups on the day of their birth and transferred to SD or kept under LD. The group reared under SD was used to produce the subsequent generation in which the ability to produce sexual morphs was tested. The group reared under LD was used to produce the subsequent generation which were also transferred to SD or kept under LD. In this way, aphids of the older-sister LD lineage were reared over a maximum of eight generations.

The ability of a lineage to produce sexual morphs was examined by using one to four asexual females from each generation for all lineages. After the larviposition onset, each mother was transferred to a new seedling every few days and a maximum of 15 nymphs were reared on a seedling. Females with embryos with compound eyes were judged to be parthenogenetic and those with eggs with no compound eye were judged to be sexual. The number of asexual or sexual progenies that each mother produced from the larviposition onset to its death was counted.

\subsection{Statistical analysis}

A generalized linear mixed model (GLMM) with a binomial distribution and logit link was applied to evaluate the effects of the number of days from hatching to the birth of mothers, rearing temperature, sister-lineages and photoperiod on the proportion of sexual progenies, using the package glmmML in $R$ 3.3.2 (R Core Team 2016). The 
random effects of individual mothers were taken into account to avoid overdispersion. The effects of days, temperature and sister-lineages were evaluated using samples of the second and subsequent generations of the older- and younger-sister SD lineages at $15^{\circ} \mathrm{C}$ and $20^{\circ} \mathrm{C}$. The effect of photoperiod was evaluated using the samples of the third and subsequent generations of the older-sister lineages under SD and LD at $20^{\circ} \mathrm{C}$.

\section{Results}

The stem mothers produced only parthenogenetic females both at $15^{\circ} \mathrm{C}$ and $20^{\circ} \mathrm{C}$ even under SD (Fig. 2). At $15^{\circ} \mathrm{C}$, the second generation also produced only parthenogenetic females, and the first sexual progenies were produced by mothers of the third generation born 51 and 57 days after hatching in the older- and in the younger-sister SD lineages, respectively (data not shown). In the older-sister SD lineage at $20^{\circ} \mathrm{C}$, the first sexual progenies were produced by a mother of the third generation born 32 days after hatching (data not shown). In the younger-sister SD lineage at $20^{\circ} \mathrm{C}$, however, mothers of the second generation born 19 days after hatching produced a small proportion of sexual morphs (data not shown). Although there was no significant difference in the proportion of sexual progenies between stem mothers in the older-sister SD lineage and control parthenogenetic females in the first generation, the latter produced a small proportion of sexual morphs under SD (Fig. 2). In the second generation under SD, however, there were significant differences in the proportions of sexual progenies between mothers in the older-sister SD lineage and control parthenogenetic females (Fig. 2). 
The proportions of sexual progenies gradually increased over successive generations for approximately 100 days after hatching in both the older- and the younger-sister sister SD lineages (Fig. 3A-D). On the same day from hatching, the proportions of sexual progenies were larger at $20^{\circ} \mathrm{C}($ Fig. $3 \mathrm{C}, \mathrm{D})$ than those at $15^{\circ} \mathrm{C}$ (Fig. 3A, B) both in the older- and the younger-sister SD lineages. The number of days from hatching to birth of mothers and temperature had a significant effect on the proportion of sexual progenies (Table 1A).

The number of days from hatching to the birth of mothers that produced $50 \%$ sexual progenies was calculated from the results of GLMM analysis (Table 2). The critical number of days for sexual morph production was not different between the older- and the younger-sister SD lineages, although the number of generations at the critical days was larger in the older-sister SD lineage than in the younger-sister SD lineage. Sister-lineage had no significant effect on the proportion of sexual progenies (Table 1A). The critical number of days for sexual morph production at $15^{\circ} \mathrm{C}$ was 1.25 1.39 times that at $20^{\circ} \mathrm{C}$, while the number of days per generation at $15^{\circ} \mathrm{C}$ was approximately 1.7 that those at $20^{\circ} \mathrm{C}($ Table 2$)$.

The proportion of sexual progenies also gradually increased over generations in the older-sister LD lineage (Fig. 3E). Mothers of the third generation first produced sexual morphs. According to the results of GLMM analysis, the photoperiod under which aphids were reared had marginally not significant effect on the proportion of sexual progenies (Table 1B). The critical number of days for sexual morph production under LD was $0.90-0.94$ times that under $\mathrm{SD}$ at $20^{\circ} \mathrm{C}$ (Table 2). 


\section{Discussion}

We showed here that in A. pisum, sexual morph production by stem mothers and by the following generations was inhibited during a few months even under short days. Such strong suppression of sexual morph production has also been shown in other aphids, e.g., A. forbesi in southern North America, Aphis chloris and M. viciae collected from England, and Myzus persicae in Greece (Lees, 1960; Marcovitch, 1924; Margaritopoulos et al., 2002; Wilson, 1938). Lees (1960) suggested that a seasonal timer for sexual morph production is adaptive to avoid producing sexual morphs under short days in early spring. On the other hand, it has also been reported that stem mothers produce sexual morphs under very short days in Drepanosiphum platanoides and Eucallipterus tiliae in Scotland (Dixon, 1972, 1971). Stem mothers of Acyrthosiphon brevicorne and Acyrthosiphon svalbardicum living in high arctic regions, where the season for growth and reproduction is shorter than in temperate regions, produce sexual morphs in natural conditions (Strathdee et al., 1993; Strathdee and Bale, 1996). Thus, the strength and duration of the seasonal timer should be adaptive to local climates.

The present results show that in A. pisum, the seasonal timer measured the number of days from hatching, not the number of generations, in accord with the reported findings in M. viciae and A. rubicola (Brodel and Schaefers, 1979; Lees, 1960). The number of generations from spring to autumn is variable among sisters in A. pisum because parthenogenetic females continue to reproduce for more than 20 days, which is longer than the time required for nymphal development (Ishikawa et al., 2012; MacKay, 1987). Thus, if the seasonal timer measured the number of generations, the response to short days might be different between the younger- and older-lineages in autumn. It is 
therefore reasonable for aphids to measure not the number of generations but the number of days to produce sexual morphs in an appropriate season.

Lees (1960) showed that the duration of the seasonal timer depends on temperature, and the present results supported this conclusion. Although the effect of temperature on the duration of the seasonal timer was not equal to that on the growth rate (Table 2), high temperature $\left(20^{\circ} \mathrm{C}\right)$ advanced the timing of sexual morph production. In $M$. viciae and A. pisum, however, higher temperature also suppresses sexual morph production: At $25^{\circ} \mathrm{C}$, sexual morphs are not produced even under $8 \mathrm{~h}$ light and $16 \mathrm{~h}$ darkness (Kenten, 1955; Lees, 1959). Considering these two findings, it is possible that high temperature has contrasting effects on the sexual morph production in parthenogenetic females before and after the seasonal timer has expired (Lees, 1960).

Although sexual morphs were produced only under short days, the seasonal timer also measured the number of days under long days in A. pisum: The ability to produce sexual morphs was recovered at a similar rate irrespective of photoperiod (Fig. 3C and 3E). In the temperate zone, sexual morph production would be suppressed under long days in summer. A seasonal timer that expires by autumn would be adaptive for responding appropriately to shortened days. The present findings were similar to those of previous studies in $M$. viciae and A. rubicola: Mothers that had been reared successively under long days and transferred to short days produced many oviparous females (Brodel and Schaefers, 1979; Lees, 1960). These results altogether showed that the sexual polyphenism in aphids is regulated by two mechanisms, and one of them depends on photoperiod whereas the other does not.

It has been reported that the maternal experience of diapause induced by short days suppresses the response to short days in the progeny generation in Diptera and 
Hymenoptera (Henrich and Denlinger, 1982; Reznik and Samartsev, 2015; Rockey et al., 1989). In Trichogramma spp. parasitoid wasps, the response to short days is suppressed over several generations after termination of a previously experienced diapause (Reznik and Samartsev, 2015). These mechanisms also seem to be adaptive to avoid responding to short days and producing nondiapause progenies in early spring. However, Reznik and Samartsev (2015) did not distinguish between the number of days and the number of generations.

Lees (1960) suggested that the seasonal timer would not result from a cytoplasmic substance which is diluted by cell division until it falls below a critical threshold, because the mechanism of the seasonal timer should resist many dilutions through several generations. Epigenetic mechanisms that alter the expression of DNA, however, can be passed on to one or more successive generations (Ho and Burggren, 2010; Sgrò et al., 2016). Although the role of epigenetic modification in reproductive polyphenism has not been studied, methylation levels in juvenile hormone associated genes are higher in winged asexual females than wingless asexual females in A. pisum (Walsh et al., 2010). In the flesh fly Sarcophaga bullata, the experience of diapause in the maternal generation changes histone acetylation in the progeny generation under the same short-day conditions (Reynolds et al., 2016). Although the physiological and molecular mechanisms of the seasonal timer in aphids are completely unknown, the present study in a model aphid species provides a basis for further investigations on the mechanisms of its seasonal timer, which might also be regulated epigenetically.

\section{Acknowledgement}


We thank Elizabeth Nakajima for linguistic corrections. This work was supported in part by a Grant-in-Aid for JSPS Fellows to N.M. (Grant Number 17J00016).

\section{References}

Bonnemaison, L., 1972. Ètude du "facteur-fondatrice" chez Dysaphis plantaginea Pass. et Acyrthosiphon pisum Harris (Homoptères, Aphididae). Ann. Entomol. Fr. 8, $607-627$.

Brodel, C.F., Schaefers, G.A., 1979. An "interval timer" for the production of oviparae in Aphis rubicola (Homoptera: Aphididae). Entomol. Exp. Appl. 25, 1-8.

Campbell, C.A.M., Tregidga, E.L., 2006. A transgenerational interval timer inhibits unseasonal sexual morph production in damson-hop aphid, Phorodon humuli. Physiol. Entomol. 31, 394-397.

Denlinger, D.L., 2002. Regulation of diapause. Annu. Rev. Entomol. 47, 93-122.

Dixon, A.F.G., 1972. The "interval timer", photoperiod and temperature in the seasonal development of parthenogenetic and sexual morphs in the lime aphid, Eucallipterus tiliae L. Oecologia 9, 301-310.

Dixon, A.F.G., 1971. The "interval timer" and photoperiod in the determination of parthenogenetic and sexual morphs in the aphid, Drepanosiphum platanoides. J. Insect Physiol. 17, 251-260.

Dixon, A.F.G., Glen, D.M., 1971. Morph determination in the bird cherry-oat aphid, Rhopalosiphum padi L. Ann. Appl. Biol. 68, 11-21. 
Henrich, V.C., Denlinger, D.L., 1982. A maternal effect that eliminates pupal diapause in progeny of the flesh fly, Sarcophaga bullata. J. Insect Physiol. 28, 881-884.

Ho, D.H., Burggren, W.W., 2010. Epigenetics and transgenerational transfer: a physiological perspective. J. Exp. Biol. 213, 3-16.

Hodek, I., Hodková, M., 1992. Regulation of postdiapause reproduction by recurrent photoperiodic response. In: Bennettová, B., Gelbič, I., Soldán, T. (Eds.), Advances in Regulation of Insect Reproduction, Institute of Entomol, Czech Acad. Sci., pp. 119-124.

IAGC, 2010. Genome sequence of the pea aphid Acyrthosiphon pisum. PLoS Biol. 8, e1000313.

Ishikawa, A., Ogawa, K., Gotoh, H., Walsh, T.K., Tagu, D., Brisson, J.A., Rispe, C., Jaubert-Possamai, S., Kanbe, T., Tsubota, T., Shiotsuki, T., Miura, T., 2012. Juvenile hormone titre and related gene expression during the change of reproductive modes in the pea aphid. Insect Mol. Biol. 21, 49-60.

Kanbe, T., Akimoto, S.I., 2009. Allelic and genotypic diversity in long-term asexual populations of the pea aphid, Acyrthosiphon pisum in comparison with sexual populations. Mol. Ecol. 18, 801-816.

Kenten, J., 1955. The effect of photoperiod and temperature on reproduction in Acyrthosiphon pisum (Harris) and on the forms produced. Bull. Entomol. Res. 46, $599-624$.

Koštál, V., 2011. Insect photoperiodic calendar and circadian clock: independence, cooperation, or unity? J. Insect Physiol. 57, 538-56.

Lamb, R.J., Pointing, P.J., 1972. Sexual morph determination in the aphid, Acyrthosiphon pisum. J. Insect Physiol. 18, 2029-2042. 
Le Trionnaire, G., Wucher, V., Tagu, D., 2013. Genome expression control during the photoperiodic response of aphids. Physiol. Entomol. 38, 117-125.

Lees, A.D., 1960. The role of photoperiod and temperature in the determination of parthogenetic and sexual forms in the aphid Megoura viciae Buckton-II. The operation of the "interval timer" in young clones. J. Insect Physiol. 4, 154-175.

Lees, A.D., 1959. The role of photoperiod and temperature in the determination of parthenogenetic and sexual forms in the aphid Megoura viciae Buckton-I. J. Insect Physiol. 3, 92-117.

Lushai, G., Hardie, J., Harrison, R.G., 1996. Inhibition of sexual morph production in the bird cherry aphid, Rhopalosiphum padi. Entomol. Exp. Appl. 81, 117-119.

MacKay, P.A., 1987. Production of sexual and asexual morphs and changes in reproductive sequence associated with photoperiod in the pea aphid, Acyrthosiphon pisum (Harris). Can. J. Zool. 65, 2602-2606.

Marcovitch, S., 1924. The migration of the Aphididae and the appearance of the sexual forms as affected by the relative length of daily light exposure. J. Agric. Res. 27, $513-522$.

Marcovitch, S., 1923. Plant lice and light exposure. Science 18, 537-538.

Margaritopoulos, J.T., Tsitsipis, J.A., Prophetou-Athanasiadou, D.A., 2002. An interval timer controls the production of sexual morphs in Myzus persicae (Homoptera: Aphididae). Physiol. Entomol. 27, 251-255.

Meyer, P., Saez, L., Young, M.W., 2006. PER-TIM interactions in living Drosophila cells: an interval timer for the circadian clock. Science 311, 226-229.

Miura, T., Braendle, C., Shingleton, A.W., Sisk, G.C., Kambhampati, S., Stern, D.L., 2003. A comparison of parthenogenetic and sexual embryogenesis of the pea aphid 
Acyrthosiphon pisum (Hemiptera: Aphidoidea). J. Exp. Zool. B. Mol. Dev. Evol. $295,59-81$.

Moran, N., 1992. The evolution of aphid life cycles. Annu. Rev. Entomol. 37, 321-348.

Mousseau, T.A., Dingle, H., 1991. Maternal effects in insect life histories. Annu. Rev. Entomol. 36, 511-34.

Nagao, T., Shimozawa, T., 1987. A fixed time-interval between two behavioural elements in the mating behaviour of male crickets, Gryllus bimaculatus. Anim. Behav. 35, 122-130.

Nijhout, H.F., 2003. Development and evolution of adaptive polyphenisms. Evol. Dev. $5,9-18$.

Nylin, S., Gotthard, K., 1998. Plasticity in life-history traits. Annu. Rev. Entomol. 43, $63-83$.

Reynolds, J.A., Bautista-Jimenez, R., Denlinger, D.L., 2016. Changes in histone acetylation as potential mediators of pupal diapause in the flesh fly, Sarcophaga bullata. Insect Biochem. Mol. Biol. 76, 29-37.

Reznik, S.Y., Samartsev, K.G., 2015. Multigenerational maternal inhibition of prepupal diapause in two Trichogramma species (Hymenoptera: Trichogrammatidae). J. Insect Physiol. 81, 14-20.

Rockey, S.J., Miller, B.B., Denlinger, D.L., 1989. A diapause maternal effect in the flesh fly, Sarcophaga bullata: Transfer of information from mother to progeny. J. Insect Physiol. 35, 553-558.

Saunders, D.S., 2014. Insect photoperiodism: effects of temperature on the induction of insect diapause and diverse roles for the circadian system in the photoperiodic response. Entomol. Sci. 17, 25-40. 
Saunders, D.S., Bertossa, R.C., 2011. Deciphering time measurement: the role of circadian "clock" genes and formal experimentation in insect photoperiodism. J. Insect Physiol. 57, 557-66.

Sgrò, C.M., Terblanche, J.S., Hoffmann, A.A., 2016. What can plasticity contribute to insect responses to climate change? Annu. Rev. Entomol. 61, 433-51.

Shingleton, A.W., Sisk, G.C., Stern, D.L., 2003. Diapause in the aphid (Acyrthosiphon pisum) is a slowing but not a cessation of development. BMC Dev. Biol. 12, 1-12.

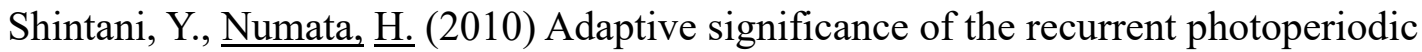
response in a spring-breeding carabid beetle, Carabus yaconinus. Entomol. Sci. 13, $367-374$.

Strathdee, A.T., Bale, J.S., 1996. Life-cycle and morph production in the Arctic aphid Acyrthosiphon brevicorne. Polar Biol. 16, 293-300.

Strathdee, A.T., Bale, J.S., Block, W.C., Webb, N.R., Hodkinson, I.D., Coulson, S.J., 1993. Extreme adaptive life-cycle in a high arctic aphid, Acyrthosiphon svalbardicum. Ecol. Entomol. 18, 254-258.

Tagu, D., Sabater-Muñoz, B., Simon, J.-C., 2005. Deciphering reproductive polyphenism in aphids. Invertebr. Reprod. Dev. 48, 71-80.

Via, S., 1992. Inducing the sexual forms and hatching the eggs of pea aphids. Entomol. Exp. Appl. 65, 119-127.

Walsh, T.K., Brisson, J.A., Robertson, H.M., Gordon, K., Jaubert-Possamai, S., Tagu, D., Edwards, O.R., 2010. A functional DNA methylation system in the pea aphid, Acyrthosiphon pisum. Insect Mol. Biol. 19, 215-228.

Wilson, F., 1938. Some experiments on the influence of environment upon the forms of Aphis chloris Koch (Aphididae). Trans. Roy. Entomol. Soc. London 87, 165-180. 


\section{Table 1}

Results of GLMM to test the effects of variables on the proportion of sexual morph progenies in Acyrthosiphon pisum.

\begin{tabular}{lllll}
\hline & \multicolumn{2}{c}{ Coefficient of variables } & & \\
\cline { 2 - 3 } Variables & Estimate & S.E. & z-value & $P$-value \\
\hline (A) & & & & \\
Intercept & -18.2 & 2.013 & -9.06 & $<0.0001$ \\
Day & 0.126 & 0.00973 & 12.92 & $<0.0001$ \\
Temperature & 0.447 & 0.0928 & 4.82 & $<0.0001$ \\
Lineage (younger) & -0.484 & 0.433 & 1.11 & 0.264 \\
\hline (B) & & & & \\
Intercept & -7.41 & 0.761 & -9.73 & $<0.0001$ \\
Day & 0.116 & 0.0118 & 9.75 & $<0.0001$ \\
Photoperiod (long-day) & 0.837 & 0.444 & -1.89 & 0.0591 \\
\hline
\end{tabular}

(A) The effects of the number of days from hatching, temperature and the sister-lineage were calculated in the older- and the younger-sister lineages under short-day conditions at $15^{\circ} \mathrm{C}$ and $20^{\circ} \mathrm{C}$. (B) The effects of the number of days from hatching and photoperiod were calculated in the older-sister lineages at $20^{\circ} \mathrm{C}$ under short-day and long-day conditions in the third and subsequent generations. 
Table 2

Duration of the seasonal timer for suppression of sexual morph production in Acyrthosiphon pisum.

\begin{tabular}{llllll}
\hline \multirow{2}{*}{ Temperature } & \multicolumn{5}{c}{ Days/generation ${ }^{\mathrm{a}}$} \\
\hline $15^{\circ} \mathrm{C}$ & \multirow{2}{*}{$10 \mathrm{~h}$ light-14 h dark } & Older-sister & $17.9 \pm 3.02$ & 90.3 & 5.0 \\
& & Younger-sister & $28.8 \pm 4.27$ & 90.7 & 3.2 \\
\hline $20^{\circ} \mathrm{C}$ & $10 \mathrm{~h}$ light-14 h dark & Older-sister & $11.1 \pm 1.92$ & 69.7 & 6.3 \\
& & Younger-sister & $18.0 \pm 4.87$ & 72.2 & 4.0 \\
\cline { 2 - 6 } & $16 \mathrm{~h}$ light-8 h dark & Older-sister & $10.7 \pm 2.45$ & 65.3 & 6.1 \\
\hline
\end{tabular}

${ }^{\mathrm{a}}$ The mean number of days per generation was calculated as the number of days from the birth to the onset of larviposition.

${ }^{b}$ The number of days from hatching of the stem mother to the birth of mothers that produced more than $50 \%$ sexual morph progenies was calculated from the results of GLMM.

${ }^{c}$ The number of generations on the critical day was calculated from the mean number of days per generation and the critical number of days. 
(A)
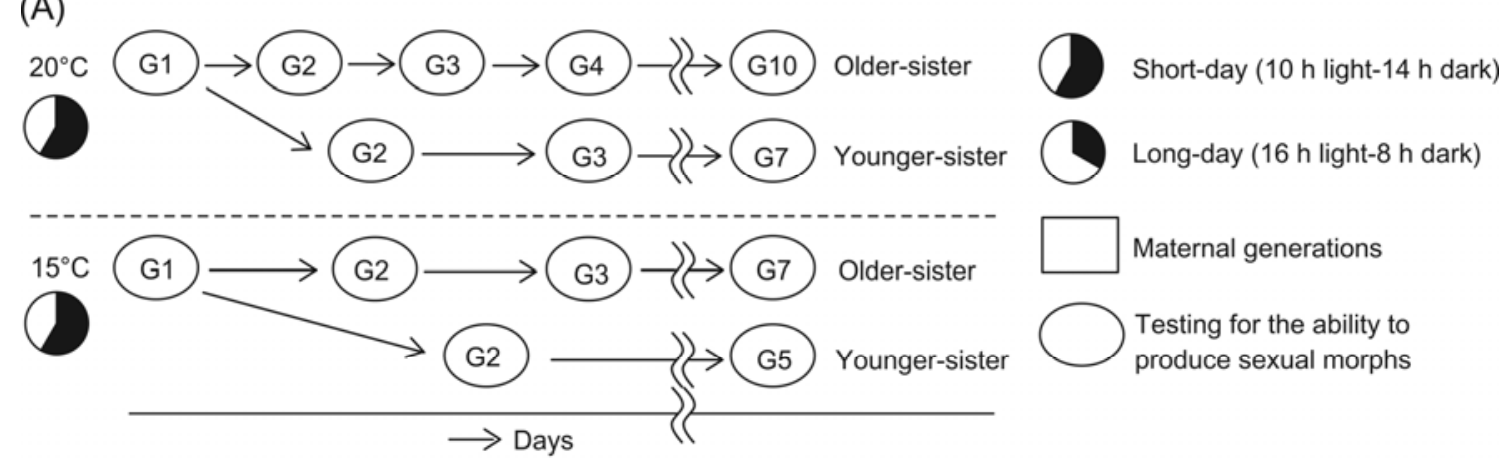

(B)

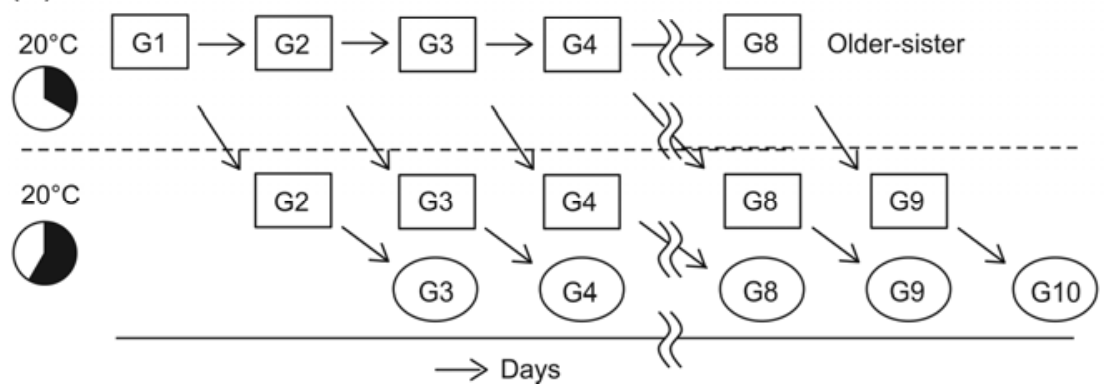

Fig. 1. A schematic representation of the experiment in Acyrthosiphon pisum. (A) In the older- and the younger-sister lineages produced under short-day conditions, aphids born within three days and approximately ten days after larviposition onset were reared successively under short-day conditions at $15^{\circ} \mathrm{C}$ or $20^{\circ} \mathrm{C}$. (B) In the older-sister lineage under long-day conditions, aphids of each generation born within three days after larviposition onset were transferred to short-day conditions, and reared for two successive generations at $20^{\circ} \mathrm{C}$. 

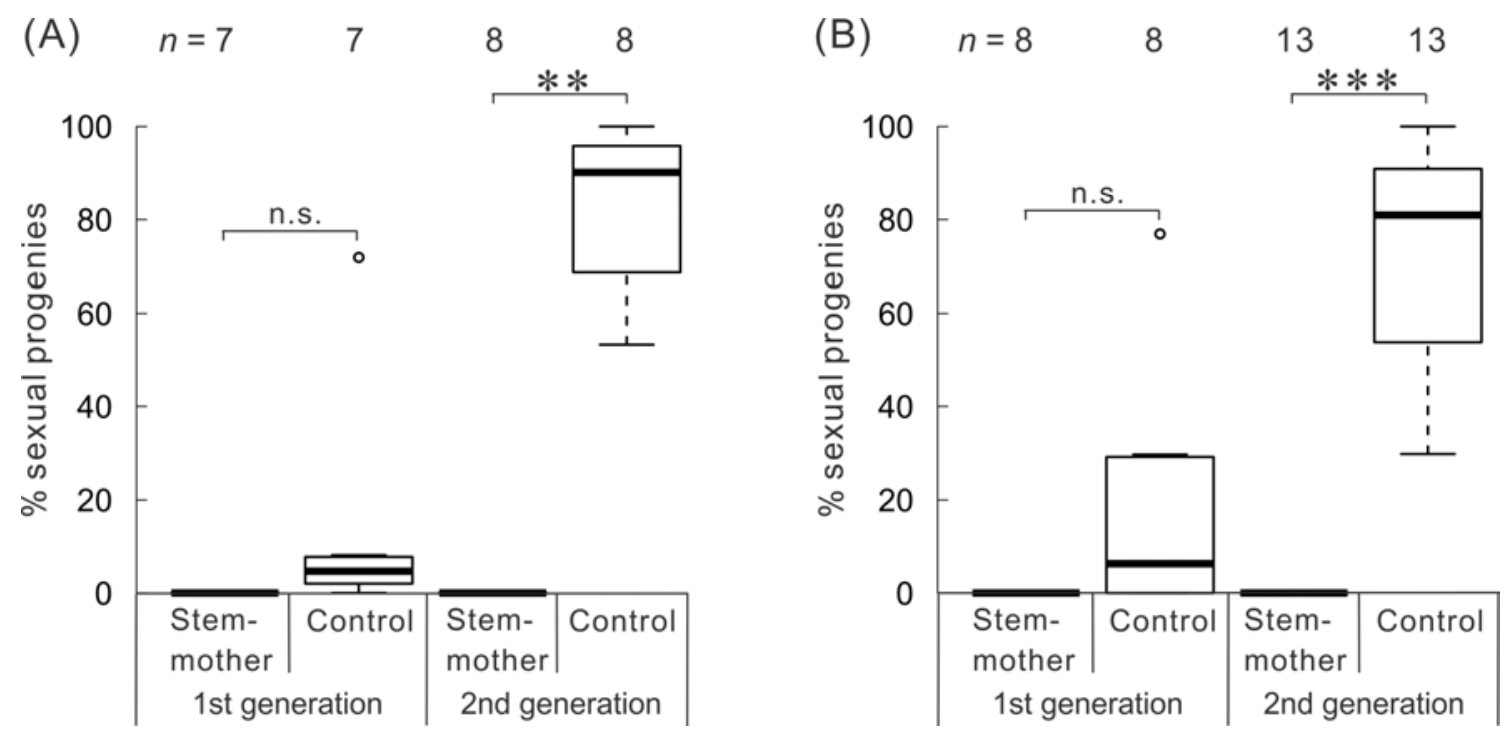

Fig. 2. The proportions of sexual morph progenies under short-day conditions at $15^{\circ} \mathrm{C}$ (A) and $20^{\circ} \mathrm{C}$ (B) in Acyrthosiphon pisum. Stem mothers and control parthenogenetic females of the clone that had been maintained parthenogenetically since 2005 were used as the first generation, and their parthenogenetic progenies that were born within three days of the larviposition onset were used as the second generation. Each mother produced $27.3 \pm 15.5$ progenies (mean \pm S.D.). Rectangular boxes represent the interquartile ranges of the data, the horizontal lines inside the boxes are the median values, and whiskers extend to the most extreme data point which is no more than 1.5 times of the interquartile range. Open circles are outliers. Significant differences between stem mothers and control parthenogenetic females are indicated by asterisks $\left({ }^{* *} P<0.01, * * * P<0.001\right.$, Mann-Whitney $U$ test). 


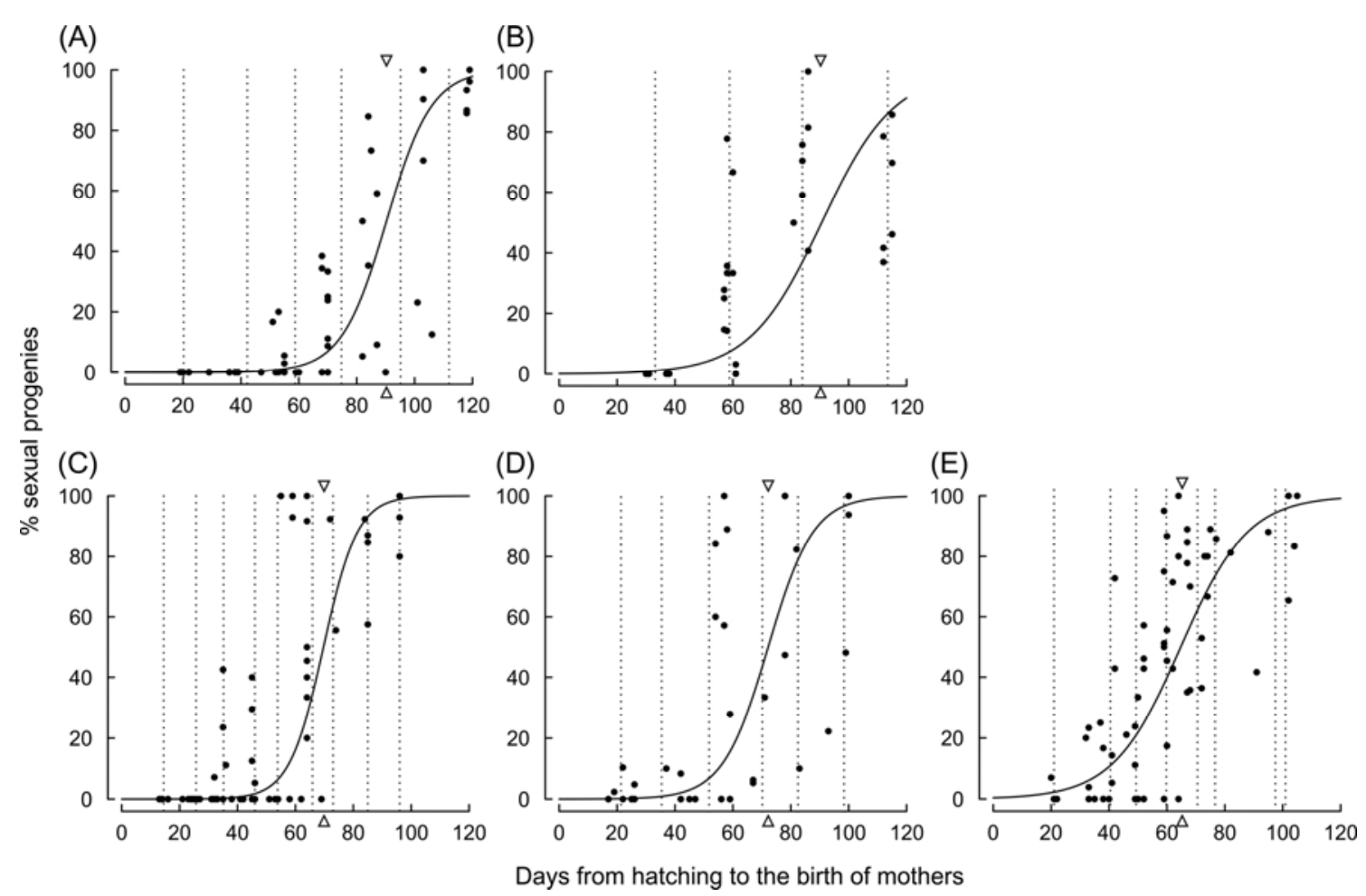

Fig. 3. Sexual morph production as a function of the number of days from hatching to the birth of mothers in Acyrthosiphon pisum. Lineages consisted of aphids that were born within three days and approximately ten days after the larviposition onset under short-day conditions at $15^{\circ} \mathrm{C}\left(\mathrm{A}, \mathrm{B}\right.$, respectively) and $20^{\circ} \mathrm{C}(\mathrm{C}, \mathrm{D}$, respectively), and aphids that were born within three days of the larviposition onset under long-day conditions at $20^{\circ} \mathrm{C}(\mathrm{E})$. The fitted curves are based on logistic regression between the proportion of sexual progenies and the number of days from hatching. Dotted lines show the mean number of days from hatching to the birth of mothers of each generation. Triangles show the critical number of days from hatching to the production of sexual morphs (see Table 2). 